\title{
Hydrogen Effects on the Failure Mechanisms in Fe-Ni Weldments
}

\author{
J.A. Fenske, ${ }^{*}$ I.M. Robertson, ${ }^{*}$ R. Ayer, ${ }^{* *}$ M. Hukle, ${ }^{* * *}$ D. Lillig, ${ }^{* * * *}$ and B. Newbury, $* * * *$ \\ * Depart. of Materials Science and Engineering, 1304 W. Green St., U. Illinois, Urbana IL 61801 \\ ** CSR, ExxonMobil Research and Engin. Company, 1545 Route 22 East, Annandale, NJ 08801 \\ ***Trendsetter Engineering, Inc., 719 Sawdust Rd. Suite 200, Spring, TX, 77380 \\ **** ExxonMobil Development Company, 12450 Greenspoint Dr., Houston, TX 77060
}

Dissimilar metal Fe-Ni weldments are commonly used to allow high-strength hardenable steels and alloys to be joined on location to field-weldable steels and alloys. A welded Ni butter layer is applied to the interface of interest on the hardenable alloy and the mechanical properties recovered by annealing prior to the closure weld being made in the field. A complex microstructure is produced along the $\mathrm{Fe}-\mathrm{Ni}$ butter interface as a result of compositional mixing during welding and diffusion and precipitation during post-weld heat treatment. This structure is poorly understood at the nanometer scale. A recent series of hydrogen-induced catastrophic failures between AISI 8630IN625 interfaces on subsea equipment has demonstrated the need for not only a better understanding of the microstructure produced along the dissimilar metal weld interface, but also their correlation to hydrogen susceptibility [1]. In this paper, key findings of a detailed microstructural characterization and fractography study are presented that enable correlation of structure-property relationships in the presence of hydrogen; a more detailed analysis can be found in [2].

A microstructural investigation of the weld interfaces revealed that they consisted of discontinuous regions of lath martensite on the Fe side of the interface followed by a $200 \mathrm{~nm}$ wide transition zone, which bridged the BCC and FCC crystal structures, and a region of continuous partial mixing on the $\mathrm{Ni}$ side of the interface, Fig. 1. Unexpectedly, nanometer sized needle-like $\mathrm{M}_{7} \mathrm{C}_{3}$ precipitates were identified along the $<100>$ directions in the continuous partial mixed region, Fig 2. Compositional analysis of this region showed it not to have the composition of IN625 but to be rich in Fe and deficient in $\mathrm{Ni}$ and $\mathrm{Cr}$, which allows these precipitates to form. To ascertain the role of these precipitates in the hydrogen failure the fracture surfaces were examined. Fractographic analysis showed two morphologies, flat surfaces and "cleavage-like" surfaces [3]. The "cleavage-like" surfaces were associated exclusively with hydrogen-induced failures but this fracture mode is unlikely as it occurred in an fcc structure. Compositional analysis associated the flat fractures with Fe-rich metal and the latter with Ni-rich metal. To associate the fracture path with the underlying microstructure, FIB machining was used to extract specimens from both flat and "cleavage-like" fracture surfaces, Fig. 3. Using these specimens the flat fractures were identified with either the discontinuous martensite-base metal interface or the transition zone-weld metal interface, Fig 4, and the "cleavage-like" with the $\mathrm{M}_{7} \mathrm{C}_{3}$-matrix interface, Fig 5. The hydrogen-induced failure can now be understood. Hydrogen will accumulate at interfaces, those between the martensite and base and weld metal, and at the carbides. This accumulation will result in a decrease in the interfacial cohesive strengths allowing failure at lower stresses. Thus, in the presence of hydrogen the carbides provide a weak path between the cracks formed at the martensite interfaces, the proposed crack path is depicted in the schematic presented in Fig.1. Elimination of the carbides through different welding procedures or post welded heat treatment may ameliorate this susceptibility to hydrogen. 


\section{REFERENCES}

[1] Lange HI, Aldstedt S, Ostby E. Investigation of fractured weld connection on Hub No. AB103 Asgard B. Trondheim, Norway: SINTEF, 2001.

[2] J.A. Fenske et al. Microstructure and hydrogen induced failure mechanisms in Fe-Ni weldments. Unpublished work.

[3] Beaugrand VCM, Smith LS, Gittos MF. Subsea Dissimilar Joints: Failure Mechanisms and Opportunities for Mitigation. Corrosion. Atlanta, Georgia: NACE International, 2009.

[4] Funding and materials for this research was provided by the ExxonMobil Development Company and The Welding Institute. The research for this publication was carried out in part in the Frederick Seitz Materials Research Laboratory, University of Illinois and the ExxonMobil Corporate Strategic Research Company, Annadale, NJ.
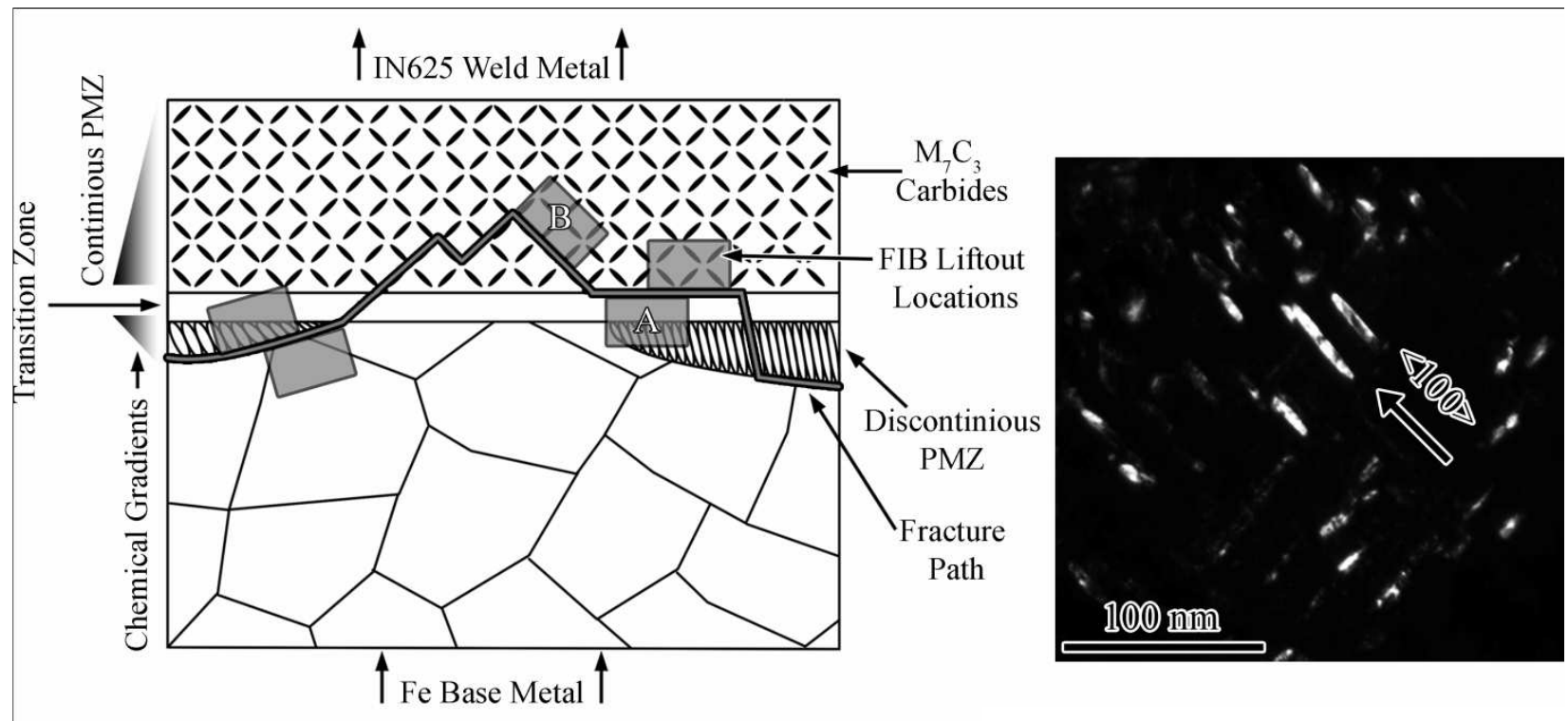

FIG 1. An illustration of the weld microstructure relative to the fracture path and FIB liftout specimens.

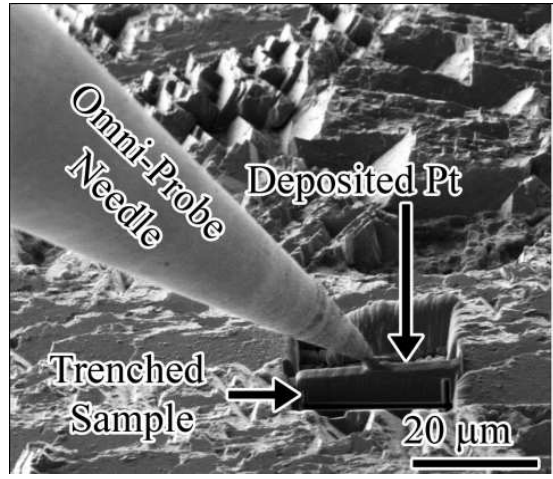

FIG 3. FIB liftout sample from the "cleavage-like" fracture surface.

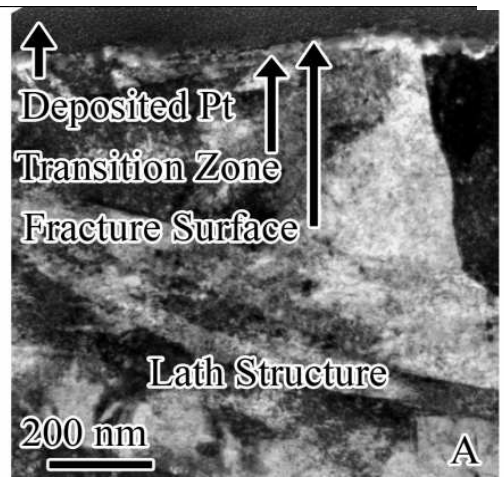

FIG 4. Bright field TEM micrograph of a FIB fracture liftout specimen from the Fe side of the lower flat fracture region.
FIG 2. $\mathrm{M}_{7} \mathrm{C}_{3}$ precipitates in the non-weld metal Ni-rich continuous PMZ.

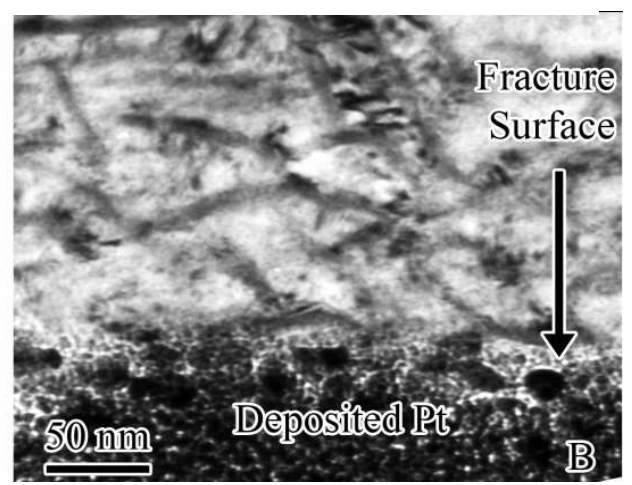

FIG 5. Bright field TEM micrograph of a FIB fracture liftout specimen from the "cleavage-like" fracture morphology. 